\title{
Insulitis in the human endocrine pancreas: Does a viral infection lead to inflammation and beta cell replication?
}

\author{
P. In't Veld
}

Received: 20 May 2011 / Accepted: 26 May 2011 / Published online: 24 June 2011

(C) Springer-Verlag 2011

\begin{abstract}
Defining the role of viruses in the aetiopathogenesis of human type 1 diabetes has been an elusive goal for more than 40 years, although indirect evidence is mounting that viruses have an important modulatory role in the development of the disease through their interaction with the innate immune system. In this issue of Diabetologia, Willcox et al. provide histopathological evidence that the islets of Langerhans in seven young patients with recentonset disease expressed the enteroviral protein VP1 and report that this marker is preferentially present in islets that show signs of enhanced replicative activity. They suggest that insulitis may be the common factor linking beta cell replication and VP1 positivity, with persistent virus infection leading to chemokine secretion, infiltration of immune cells (insulitis) and pro-inflammatory cytokine-induced beta cell replication.
\end{abstract}

Keywords Beta cells · Enterovirus · Human · Insulitis ·

Replication · Type 1 diabetes · Viral infection

Human type 1 diabetes is considered to be a Tcell-mediated autoimmune disease leading to the destruction of approximately $75 \%$ of the beta cell mass at clinical onset. The cellular autoimmunity is accompanied by humoral autoimmunity directed against several beta cell autoantigens, mainly associated with the secretory granule membrane or content. Whether the humoral autoimmunity is a cause or a

\section{P. In't Veld $(\bowtie)$}

Department of Pathology, Vrije Universiteit Brussel,

Laarbeeklaan 103,

B-1090 Brussels, Belgium

e-mail: intveld@vub.ac.be consequence of beta cell death is not known, nor is it known what the precipitating autoantigen is against which the cellular immune response is directed. The disease has a polygenic background, and environmental factors have been shown to play an important role.

Since the observation in 1969 that there is a significant correlation between the seasonal incidence of the onset of type 1 diabetes and the prevalence of coxsackie B4 virus infection [1], there has been an ongoing search for evidence linking enteroviral infections to the aetiopathogenesis of the disease. Unfortunately, the evidence has remained largely circumstantial and Koch's four postulates have been met only in sporadic cases, the best known being that of a 10 -year-old boy in whom coxsackie B4 virus was isolated from the pancreas and led to insulitis and beta cell death in mice inoculated with the virus [2]. Many different types of viruses, including rubella virus, cytomegalovirus, mumps virus and enterovirus, and other microorganisms have since been implicated in the development of type 1 diabetes, leading to the concept that infections in general can have a modulatory role in the development of the disease through their interaction with the innate immune system and/or by indirect modulation of the adaptive immune response [3].

In this issue of Diabetologia, Willcox et al. [4] describe seven patients with recent-onset type 1 diabetes and insulitis. They investigated the presence of the enteroviral capsid protein VP1 by immunohistochemistry and report that this marker is preferentially present in beta cellcontaining islets that show signs of enhanced replicative activity. As these authors had previously shown that islets with enhanced replicative activity predominantly corresponded to islets with insulitis [5], they suggested that insulitis might be the common factor linking beta cell replication and VP1 positivity, with persistent virus infec- 
tion leading to chemokine secretion, infiltration of immune cells (insulitis) and pro-inflammatory cytokine-induced beta cell replication.

Although limited in scope, the study is interesting for several reasons. First, it emphasises the importance of collecting histopathological specimens from the pancreas of individuals with type 1 diabetes, a resource that is distinctly underdeveloped considering the extent and impact of this major disease. Although there is general agreement that the presence of an inflammatory infiltrate in the islets of Langerhans is the characteristic histopathological lesion in recent-onset disease in children [6], it is not always realised that this perception is based on a small number of individuals, with perhaps only 150 cases of insulitis having been reported over the past 110 years. Many of the early cases were studied only with classical histological stains and were subsequently lost to follow-up. Only a few cases have been studied with more modern analytical techniques. It is therefore of considerable importance that material from one of the largest and best documented collections of human specimens, collected from children with type 1 diabetes some 25 years ago in the UK [7], was available for the present study.

The study confirms earlier work from the same group, in which immunopositivity for the enteroviral marker VP1 was found in islet cells from 44 out of 72 young individuals with recent-onset type 1 diabetes mellitus, 10 out of 25 individuals with type 2 diabetes mellitus and three out of 50 controls [8]. Similarly, the VP1 positivity in the present study was found in the islets of all seven patients with type 1 diabetes who were investigated. However, the number of positive islets was low, with only $6 \%$ of islets showing one or more positive cells. These positive cells were preferentially located in beta cell-containing islets showing positivity for the replication marker $\mathrm{Ki} 67$, with $40 \%$ of such islets being positive for VP1. The nature of the VP1-positive cells could not be identified unequivocally, but they did not correspond to any of the Ki67-positive cells present in the islets.

As was pointed out in an earlier commentary in this journal [9], it is difficult to ascertain the specificity of the VP1 immunoreactivity, and cross-reactivity of the antibody to non-viral epitopes cannot be excluded. The presence of a virus should therefore be confirmed by other methods, such as RT-PCR or in situ hybridisation using the same material. Such additional proof is, however, lacking [10]. Although the data on VP1 immunopositivity are interesting and add to the considerable body of evidence pointing to a viral aetiology of type 1 diabetes, they do not form conclusive proof of the presence of enterovirus in the pancreatic beta cells of diabetic individuals.

One of the main obstacles in obtaining proof is the nature of the material available for study, consisting of formalin-fixed, paraffin-embedded autopsy specimens. This does not constitute the best starting material for a molecular analysis, with proteins being denatured and chemically modified, nucleic acids being fragmented, and the overall preservation and morphology being affected by the rapid autolysis characteristic of the pancreatic organ. Our collections of pancreatic samples from individuals with recent-onset type 1 diabetes are inadequate, in terms of both the number of cases and the sample quality, to perform the key experiments that are necessary to find conclusive proof. Collaborative efforts to collect such material will be essential for research to progress.

The observation that the rare VP1-positive cells present in the islets of patients with diabetes co-localise to islets with equally rare Ki67 positivity was an unexpected finding. The true relevance of this observation may lie in a previous observation that $\mathrm{Ki} 67$ positivity is predominantly found in insulitic islets [5]. A link between VP1 positivity, insulitis and replication would constitute an important new finding as it suggests a chain of events in which a viral infection precipitates a local inflammatory reaction that initially has a generalised stimulatory effect on islet cell replication, but in a later phase may result in beta cell death.

Such a model is supported by a number of recent reports. The first is that of beta cell replication in an autoantibodypositive organ donor [11]. The donor was positive for four autoantibodies and had a susceptible HLA-DQ genotype; he showed insulitis in $9 \%$ of his islets. Interestingly, the inflamed islets showed a high level of beta cell replication (5\% Ki67-positive beta cells), contrasting with a complete absence of replication in non-inflamed islets, which suggests that chemokines released by the infiltrating cells induced the replication. High levels of beta cell replication were also found before the onset of diabetes in the spontaneously diabetic NOD mouse model, with replication levels reaching 3\% of Ki67-positive beta cells prior to the clinical onset of disease [12]. Finally, a link between inflammation and replication is suggested by observations in the non-diabetic human donor pancreas in which a generalised inflammatory infiltration induced by prolonged life support was associated with a generalised increase in the replication of pancreatic cell types [13].

Clearly, more studies are needed to address this important issue as they suggest that, in the early phases of the disease, islet inflammation induces beta cell replication. This suggests that mechanisms in individuals with recentonset type 1 diabetes are attempting to regenerate the beta cells mass, a process that, if stimulated, has the potential to modulate disease outcome significantly, provided that concurrent beta cell destruction is stopped. Such a model would conform to the prescient observation made by one of the great pioneers of the histopathology of type 1 diabetes, Philip LeCompte, that the real question to ask in the context 
of type 1 diabetes is not why beta cells disappear, but why beta cells are inhibited from regenerating [14].

Acknowledgements P. V. was involved in the analysis and interpretation of data. He drafted the article and revised it critically for important intellectual content, and gave final approval for the version to be published.

Duality of interest The author declares that there is no duality of interest associated with this manuscript.

\section{References}

1. Gamble DR, Taylor KW (1969) Seasonal incidence of diabetes mellitus. Br Med J 3:631-633

2. Yoon JW, Austin M, Onodera T, Notkins AL (1979) Virusinduced diabetes mellitus: isolation of a virus from the pancreas of a child with diabetic ketoacidosis. N Engl J Med 300:11731179

3. Lehuen A, Diana J, Zaccone P, Cooke A (2010) Immune cell crosstalk in type diabetes. Nat Rev Immunol 10:501-513

4. Willcox A, Richardson SJ, Bone AJ, Foulis AK, Morgan NG (2011) Immunohistochemical analysis of the relationship between islet cell proliferation and the production of the enteroviral capsid protein, VP1, in the islets of patients with recent-onset type 1 diabetes. Diabetologia. doi:10.1007/s00125-011-2192-7

5. Willcox A, Richardson SJ, Bone AJ, Foulis AK, Morgan NG (2010) Evidence of increased islet cell proliferation in patients with recent-onset type 1 diabetes. Diabetologia 53:2020 2028

6. Gepts W (1965) Pathologic anatomy of the pancreas in juvenile diabetes mellitus. Diabetes 14:619-633

7. Foulis AK, Liddle CN, Farquharson MA, Richmond JA, Weir RS (1986) The histopathology of the pancreas in type 1 (insulindependent) diabetes mellitus: a 25-year review of deaths in patients under 20 years of age in the United Kingdom. Diabetologia 29:267-274

8. Richardson SJ, Willcox A, Bone AJ, Foulis AK, Morgan NG (2009) The prevalence of enteroviral capsid protein vp1 immunostaining in pancreatic islets in human type 1 diabetes. Diabetologia 52:1143-1151

9. Roivainen M, Klingel K (2009) Role of enteroviruses in the pathogenesis of type 1 diabetes. Diabetologia 52:995-996

10. Foulis AK, McGill M, Farquharson MA, Hilton DA (1997) A search for evidence of viral infection in pancreases of newly diagnosed patients with IDDM. Diabetologia 40:53-61

11. In't Veld P, Lievens D, De Grijse J, Ling Z, Van der Auwera B, Pipeleers-Marichal M, Gorus F, Pipeleers D (2007) Screening for insulitis in adult autoantibody-positive organ donors. Diabetes 56:2400-2404

12. Sreenan S, Pick AJ, Levisetti M, Baldwin AC, Pugh W, Polonsky KS (1999) Increased beta cell proliferation and reduced mass before diabetes onset in the nonobese diabetic mouse. Diabetes 48:989 996

13. In’t Veld PA, De Munck N, van Belle K et al (2010) Beta cell replication is increased in donor organs from young patients after prolonged life support. Diabetes 59:1702-1708

14. LeCompte PM (1958) "Insulitis" in early juvenile diabetes. Arch Pathol Lab Med 66:450-457 